\title{
Design and Fabrication of Air-Based 1-3 Piezoelectric Composite Transducer for Air-Coupled Ultrasonic Applications
}

\author{
Cunfu He, Yaoyao Wang, Yan Lu, Yuepeng Liu, and Bin Wu \\ College of Mechanical Engineering and Applied Electronics Technology, Beijing University of Technology, Beijing 100124, China \\ Correspondence should be addressed to Yan Lu; lvyan@bjut.edu.cn
}

Received 20 February 2016; Revised 12 May 2016; Accepted 26 May 2016

Academic Editor: Manel del Valle

Copyright (c) 2016 Cunfu He et al. This is an open access article distributed under the Creative Commons Attribution License, which permits unrestricted use, distribution, and reproduction in any medium, provided the original work is properly cited.

\begin{abstract}
The air-based 1-3 piezoelectric composite transducers are designed and fabricated in order to solve the acoustic impedance matching problem. Firstly, a finite element model using honeycomb structure as the piezoelectric composite matrix is built to reduce the acoustic impedance of the sensitive element. Three important factors, volume fraction of piezoelectric materials $\varphi$, the thickness $h$, and the size $s$ of the square cross section of piezoelectric column, are examined and verified in simulation. Then, according to the result of simulation, the piezoelectric composites and the air-coupled transducers are fabricated. The honeycomb structures of resin are produced by the method of 3D printing technology, with the volume fraction of air being $30 \%$. The impedance characteristics and the excitation/reception performance of the air-coupled transducers are measured and optimized. Meanwhile, a scanning experiment is carried out to demonstrate the crack detection process in monocrystalline silicon. $A_{0}$ mode of Lamb waves is excited and collected. The location and size of the defect will be determined by calculating the correlation coefficients of the received signals and reference signals. Finally, a $15 \mathrm{~mm} \times 0.5 \mathrm{~mm} \times 0.5 \mathrm{~mm}$ scratch is clearly distinguished.
\end{abstract}

\section{Introduction}

Silicon is one of the most important components of solar cells, and the original integrality of silicon wafer affects the photoelectric conversion efficiency and service life significantly. So, a suitable nondestructive testing and evaluation method should be performed to inspect the cracks in silicon wafer.

In many researches, the damage detection for silicon wafer is mainly classified into several methods, which include resonance ultrasonic vibrations [1] and ultrasonic guided waves [2]. With the increasing demand for highspeed inspection, nondestructive inspection modes using ultrasonic guided waves have become a research hotspot. The nondestructive inspection modes can be broadly divided into contact methods and noncontact methods. At present, the methods of noncontact ultrasonic testing are mainly aircoupled ultrasonic testing [3], laser ultrasonic testing [4], and electromagnetic ultrasonic testing [5].

Air-coupled ultrasonic testing avoids the specimen contact in order to wipe the influence of contact conditions and coupling materials. Then, only air will be used as the coupling medium, and the transducer can easily move to make it possible to do scanning quickly. Air-coupled ultrasonic testing includes penetration detection, pulse-echo testing, and oblique incident detection. Kichou et al. [6] used aircoupled transducers to excite pure Lamb waves in plate. The relationship between the deviation of Lamb wave beam and the inclination angle of specimen is researched. Solodov et al. [7] demonstrated the periodic distribution of Lamb wave amplitudes and phases along the various directions in silicon wafer by air-coupled transducers. Yan et al. [8] investigated the impact of delamination in a carbon-epoxy composite plate. The group velocity of air coupling Lamb waves is extracted to identify the positions of defects. Chakrapani et al. [9] experimentally located the crack in both monocrystalline and polycrystalline silicon wafer with the thickness of $200 \mu \mathrm{m}$ using linear scanning method by $A_{0}$ mode Lamb waves. Liu et al. [10] utilized the air-coupled ultrasonic transducers to generate and receive Lamb waves in composite beams for delamination detection and analyzed the reflection and mode conversion at the ends of lamination defects.

However, the main restriction associated with air coupling method is the large acoustic impedance mismatch at 
the transducer/air and air/specimen interfaces, where most of the incident wave will be reflected [5]. When the ultrasound passes through an interface, only a proportion of it can be coupled into the next material. This "proportion" depends on how close the acoustic impedance of these two materials is. The acoustic impedance of traditional piezoelectric ceramic materials is almost $(30 \sim 40) \times 10^{6}$ Rayl, but that of air is only 420 Rayl. So the proportion of the ultrasound that is coupled into the air will be only $0.003 \% \sim 0.005 \%$.

The active materials, 1-3 type piezoelectric composites, composed of polymer (epoxy resin or polyurethane) and piezoelectric ceramic, can reduce the acoustic impedance significantly. Hence, the transmitted proportion (from transducer to air) can be increased. Generally, the 1-3 type piezoelectric composites possess the following attributes: low density, low acoustic impedance, wide bandwidth, and high electromechanical coupling coefficient. Newnham et al. [11] first put forward the concept of 1-3 piezoelectric composites. Based on their study, extensive researches have been carried out. Hayward and Bennett [12] analyzed the working characteristic of 1-3 piezoelectric composite transducers by finite element method. Hladky-Hennion and Decarpigny [13] observed the influence of geometrical parameters on 1-3 piezoelectric composites by establishing a cycle model. Bhardwaj [14] firstly proposed the prototype of air-based piezoelectric composites sensors, using honeycomb structure or foam material as the substrate to reduce the density and acoustic impedance.

To sum up, in this paper, air-based 1-3 piezoelectric composites air-coupled transducer will be introduced and evaluated. Firstly, the structure of piezoelectric composites is manipulated. Secondly, 3D finite element models are created to analyze the performance of air-based 1-3 piezoelectric composites. Then, the transducers based on 1-3 piezoelectric composites are fabricated with the honeycomb structures of resin which are produced by $3 \mathrm{D}$ printing. Also, the excitation and reception performance are tested. Finally, these transducers will be applied in the crack detection by generating and receiving Lamb waves.

\section{3D Simulations of 1-3 Piezoelectric Composites}

2.1. 1-3 Piezoelectric Composites and Their Finite Element Model (FEM). As shown in Figure 1, conventional 1-3 piezoelectric composites are composed of piezoelectric columns, which are mounted inside the polymer parallelly and periodically. The structure can reduce the density and decrease the acoustic impedance effectively. This will close the impedance between piezoelectric transducer and the air, so as to let more ultrasound through.

In order to reduce the acoustic impedance of the piezoelectric composites significantly, air-based 1-3 piezoelectric composites should be induced. The structure and components of air-based 1-3 piezoelectric composites are shown in Figure 2. Using honeycomb structure as a matrix of piezoelectric composites, the piezoelectric columns are embedded in the cellular structure. The honeycomb structure acts as a

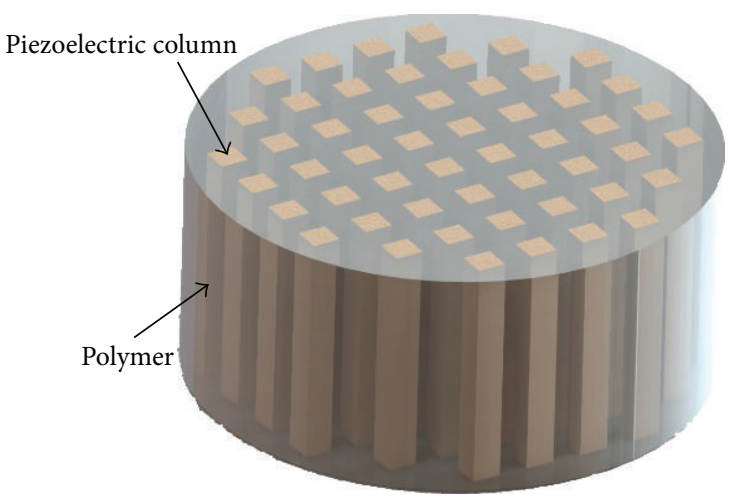

FIGURE 1: Conventional 1-3 piezoelectric composites.

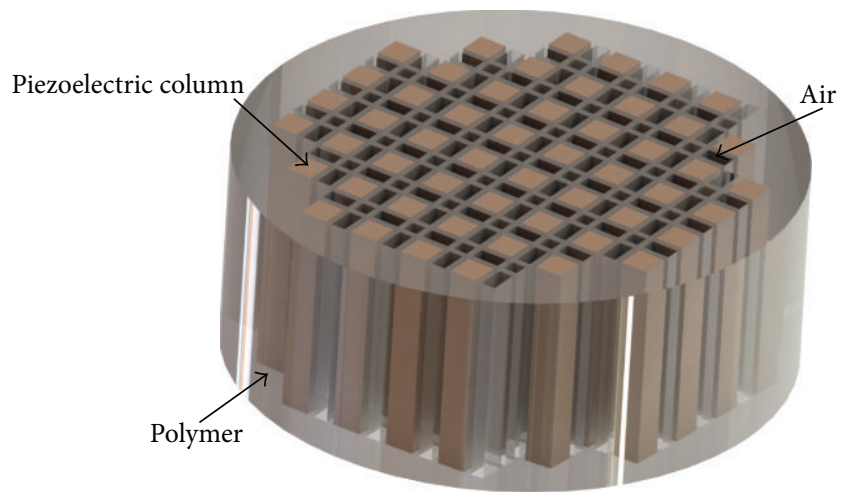

FIgURE 2: Air-based 1-3 piezoelectric composites.

skeleton to support the piezoelectric column. However, the air gap (instead of the filling polymer in Figure 1) reduces the density and the acoustic impedance efficiently. Thus, the air becomes the main part of the composite matrix. And this is where the "air base" comes from.

According to 1-3 piezoelectric composites thicknessmode oscillation theory [15], the acoustic impedance of 1-3 piezoelectric composites can be formulated by

$$
\bar{Z}=\left(\bar{c}_{33} \bar{\rho}\right)^{1 / 2},
$$

where $\bar{Z}, \bar{c}_{33}$, and $\bar{\rho}$ are the generalized acoustic impedance, elastic constants, and density, respectively. $\bar{c}_{33}$ and $\bar{\rho}$ of $1-$ 3 piezoelectric composites are determined by the volume fraction and the original elastic constants and density of each own phase. Compared with the conventional 1-3 piezoelectric composites, the air-based 1-3 piezoelectric composites use honeycomb structure as a matrix, which will inevitably reduce the acoustic impedance. For example, when $\varphi=$ $40 \%$, epoxy $30 \%$, and air $30 \%$, we can obtain the generalized acoustic impedance which equals $1.28 \times 10^{7} \mathrm{~kg} \cdot \mathrm{m}^{-2} \cdot \mathrm{s}$, while the conventional one equals $1.37 \times 10^{7} \mathrm{~kg} \cdot \mathrm{m}^{-2} \cdot \mathrm{s}$. It shows a $7 \%$ decrease. Therefore, at the same PZT volume fraction, the acoustic impedance of air-based 1-3 piezoelectric composites is lower than that of epoxy-based 1-3 piezoelectric composites. 
TABLE 1: Material parameters of PZT-5H.

\begin{tabular}{lccccccccccc}
\hline$\rho$ & \multicolumn{1}{c}{$c$} & \multicolumn{2}{c}{$c, 10^{10} \mathrm{~N} / \mathrm{m}^{2}$} & \multicolumn{4}{c}{$e, \mathrm{C} / \mathrm{m}^{2}$} & $\varepsilon_{11}$ & $\varepsilon_{33}$ \\
$\mathrm{~kg} / \mathrm{m}^{3}$ & $c_{11}$ & $c_{12}$ & $c_{13}$ & $c_{33}$ & $c_{44}$ & $c_{66}$ & $e_{33}$ & $e_{31}$ & $e_{15}$ & $\varepsilon_{13}$ \\
\hline 7500 & 12.6 & 7.95 & 8.41 & 11.7 & 2.3 & 2.35 & 23.3 & -6.5 & 17 & 1700 & 1470 \\
\hline
\end{tabular}

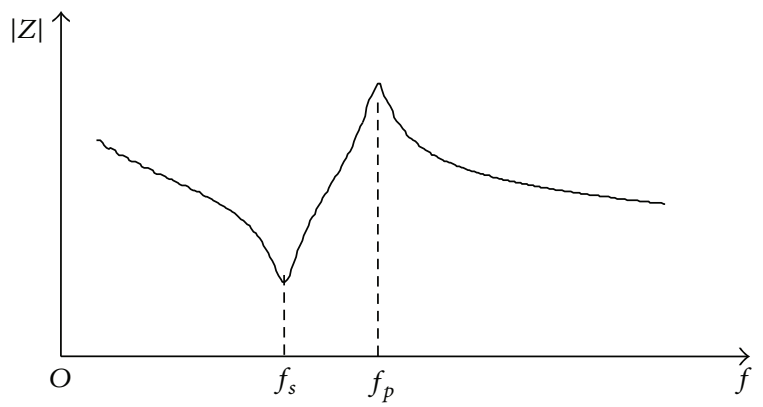

FIgURE 3: Typical characteristic impedance curve of piezoelectric materials.

When an electrical signal is applied to the piezoelectric materials, the equivalent impedance of the piezoelectric element will change along with the exciting frequency. The characteristic impedance curve of piezoelectric materials is shown in Figure 3. The minimum of this curve corresponds to the series resonant frequency $f_{s}$, while the maximum of impedance represents the parallel resonant frequency $f_{p}$.

In this research, the electromechanical coupling coefficient $K_{t}$ and the mechanical quality factor $Q_{m}$ are selected as the critical factor to evaluate the performance of the piezoelectric composites. $K_{t}$ is a quantity that measures the conversion efficiency between electrical energy and acoustic energy in piezoelectric materials. For thickness vibration mode of 1-3 piezoelectric composites, the electromechanical coupling coefficient $K_{t}$ can be formulated by

$$
K_{t}^{2}=\frac{\pi}{2} \frac{f_{s}}{f_{p}} \tan \left(\frac{\pi}{2} \frac{f_{p}-f_{s}}{f_{p}}\right) .
$$

$Q_{m}$ is a quantity that measures the wastage of energy overcoming the internal friction when the piezoelectric materials resonate. Usually, this part of energy turns out to be heat. The mechanical quality factor $Q_{m}$ can be formulated by

$$
Q_{m}=\frac{f_{p}^{2}}{2 \pi f_{s}|Z| C^{T}\left(f_{p}^{2}-f_{s}^{2}\right)},
$$

where $|Z|$ is the minimum of the resonant impedance; $C^{T}$ is the free capacitance. Accordingly, when $Q_{m}$ is greater, more energy turns into mechanical oscillation.

Air-based 1-3 piezoelectric composites are formed by the same structural unit in a certain periodical arrangement. In this repeatable unit, there exist two symmetrical planes, as shown in Figure 4. One-quarter of the unit is called a cell. If symmetrical boundary conditions are set to the finite element model, actually, the performance of the air-based 13 piezoelectric composites can be obtained by only one cell
TABLE 2: Material parameters of epoxy resin.

\begin{tabular}{ccccc}
\hline & $\rho, \mathrm{kg} / \mathrm{m}^{3}$ & $c_{T}, \mathrm{~m} / \mathrm{s}$ & $c_{L}, \mathrm{~m} / \mathrm{s}$ & $\varepsilon / \varepsilon_{0}$ \\
\hline CY1301/HY1300 & 1140 & 1140 & 2370 & 4 \\
\hline
\end{tabular}

model. In order to study the performance of 1-3 piezoelectric composites, $\mathrm{PZT}-5 \mathrm{H}$ is selected as the piezoelectrics, while epoxy resin is the polymer matrix. The material parameters are shown in Tables 1 and 2. The 3D FE simulations are carried out using COMSOL Multiphysics (COMSOL Inc., Sweden), with symmetrical boundary conditions. The finite element model of one cell of air-based 1-3 piezoelectric composites is illustrated in Figure 4. In FE model, the volume fraction $\varphi$ of PZT is gradually increased from $10 \%$ to $60 \%$ with the interval of $10 \%$, the cross-sectional area $s$ of the piezoelectric square column is increased from $1 \mathrm{~mm} \times 1 \mathrm{~mm}$ to $3 \mathrm{~mm}$ $\times 3 \mathrm{~mm}$, with the side length stepping by $0.5 \mathrm{~mm}$, and the thickness $h$ of piezoelectric column is increased from $5 \mathrm{~mm}$ to $10 \mathrm{~mm}$, with the interval of $1 \mathrm{~mm}$. The element chose a 3-dimensional brick type. The element sizes in length ( $x$ direction), in width ( $y$ direction), and in thickness $(z$ direction) are all $0.2 \mathrm{~mm}$, approximately $1 / 10$ wavelength. The scanning frequency ranges from $50 \mathrm{kHz}$ to $500 \mathrm{kHz}$, with the interval of $1 \mathrm{kHz}$.

2.2. Influence of PZT Volume Fraction $\varphi$. In the composite material, the content of piezoelectrics directly affects the piezoelectric properties. With the increase of volume fraction of PZT, the piezoelectric constant and dielectric constant of composite material will increase. Meanwhile, the acoustic impedance of the composite material will also increase. So a suitable volume fraction of PZT should be optimized to balance the piezoelectric constant/dielectric constant and the acoustic impedance.

In the finite element model of piezoelectric composite, the thickness $h$ and the cross-sectional area $s$ (red area) of the piezoelectric column are $10 \mathrm{~mm}$ and $1 \mathrm{~mm} \times 1 \mathrm{~mm}$. The volume fraction of PZT $\varphi$ is gradually increased from $10 \%$ to $60 \%$ with the interval of $10 \%$, while keeping the volume fraction of air 30\%, as shown in Figure 5.

The simulation results are shown in Figures 6 and 7 . With the increase of volume fraction $\varphi$ of the PZT, the electromechanical coupling coefficient $K_{t}$ of 1-3 piezoelectric composites will gradually increase, while the mechanical quality factor $Q_{m}$ will gradually decrease. When volume fraction $\varphi$ of the PZT is $40 \% \sim 60 \%$, the electromechanical coupling coefficient $K_{t}$ tends to be stable and maximum, which means this electromechanical conversion efficiency is optimized. But the mechanical quality factor $Q_{m}$ changes slightly and is much lower than PZT-5H. Meanwhile, at the same volume fraction, the electromechanical coupling 


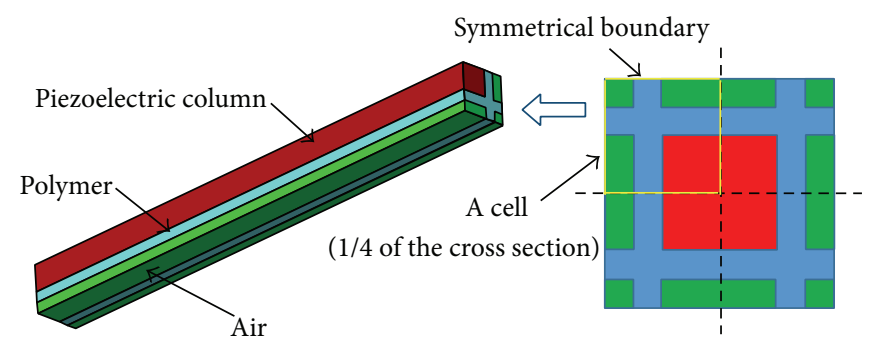

Figure 4: A quarter cycle finite element model of 1-3 piezoelectric composite.
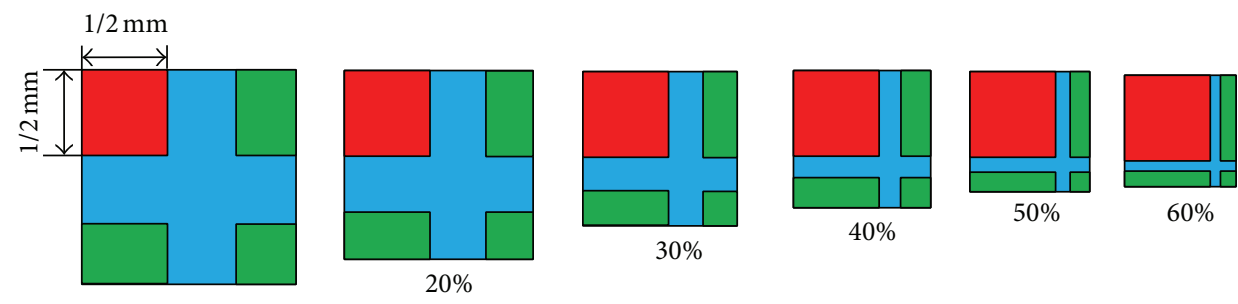

$10 \%$

FIGURE 5: Increase of PZT volume fraction $\varphi$.

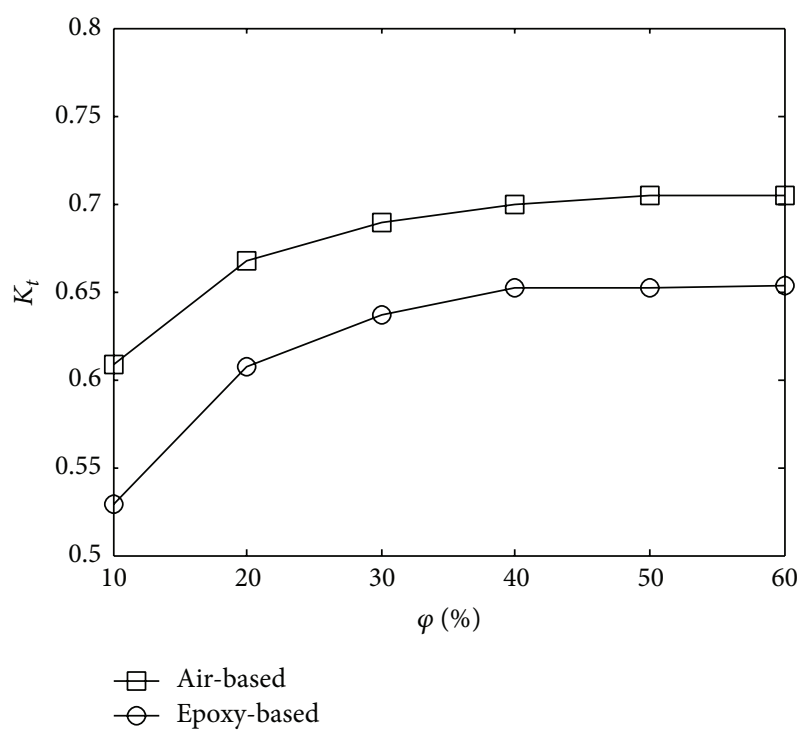

FIGURE 6: Influence of the PZT volume fraction on the electromechanical coupling coefficient.

coefficient $K_{t}$ of air-based 1-3 piezoelectric composites is greater than that of epoxy-based 1-3 piezoelectric composites for almost $10 \%$. The volume fraction of $40 \%$ for PZT is selected to ensure both high electromechanical conversion efficiency and low acoustic impedance.

2.3. Influence of PZT Cross-Sectional Area s. In the finite element model, the thickness $h$ and the volume fraction $\varphi$ of PZT are $10 \mathrm{~mm}$ and $40 \%$. The cross-sectional area $s$ of the piezoelectric square column is gradually increased from $1 \mathrm{~mm}$ $\times 1 \mathrm{~mm}$ to $3 \mathrm{~mm} \times 3 \mathrm{~mm}$, with the side length stepping by $0.5 \mathrm{~mm}$, as shown in Figure 8 .

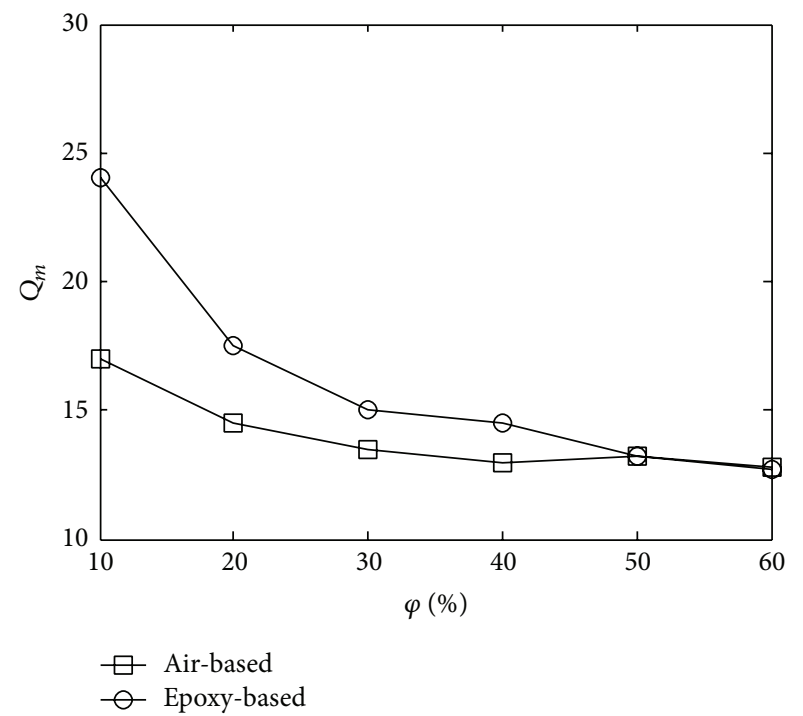

Figure 7: Influence of the PZT volume fraction on the mechanical quality factor.

The relationship between the electromechanical coupling coefficient $K_{t}$ and the cross-sectional area $s$ is shown in Figure 9. The change of $s$ of PZT has little impact on $K_{t}$. And the electromechanical conversion efficiency of air-based 1-3 piezoelectric composites is greater than that of epoxybased ones. The influence of the cross-sectional area $s$ on the mechanical quality factor $Q_{m}$ is shown in Figure 10. The change of $s$ of PZT also shows little impact on $Q_{m}$.

In the composite material, the PZT cross-sectional area $s$ mainly affects the vibration mode. In general, for piezoelectrics, the vibration mode includes thickness vibration mode and lateral vibration mode [16]. Generally, the greater 

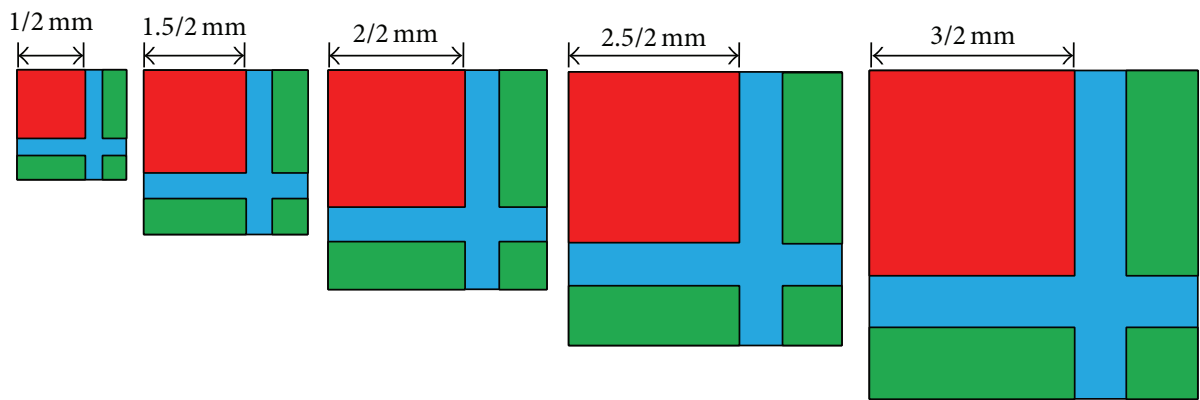

FIGURE 8: Increase of PZT cross-sectional area $s$.

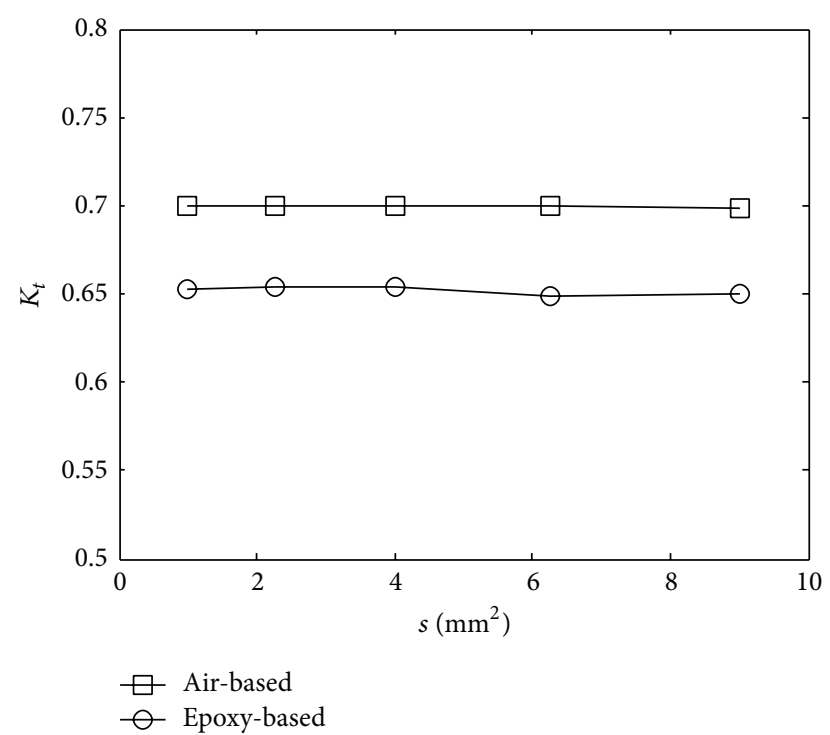

FIGURE 9: Influence of the PZT cross-sectional area on the electromechanical coupling coefficient.

the thickness electromechanical coupling coefficient, the stronger the thickness vibration mode; the greater the planar electromechanical coupling coefficient, the stronger the lateral vibration mode. For 1-3 piezoelectric composites, when the PZT cross-sectional area is larger, which means the larger aspect ratio (side length/thickness), the lateral vibration mode will affect the thickness vibration mode significantly, leading to the fact that the thickness vibration mode will be limited. So, it is important to fabricate "long and thin" PZT column. Considering both the processing procedures and the cost, the cross-sectional area of $1 \mathrm{~mm} \times 1 \mathrm{~mm}$ is selected for the PZT column.

2.4. Influence of PZT Thickness $h$. The frequency constant of PZT-5H is $N=2000 \mathrm{~Hz} \cdot \mathrm{m}$. The relationship between the resonant frequency $f_{0}$ of thickness vibration mode and the thickness of PZT $h$ can be formulated by

$$
N=f_{0} \cdot h
$$

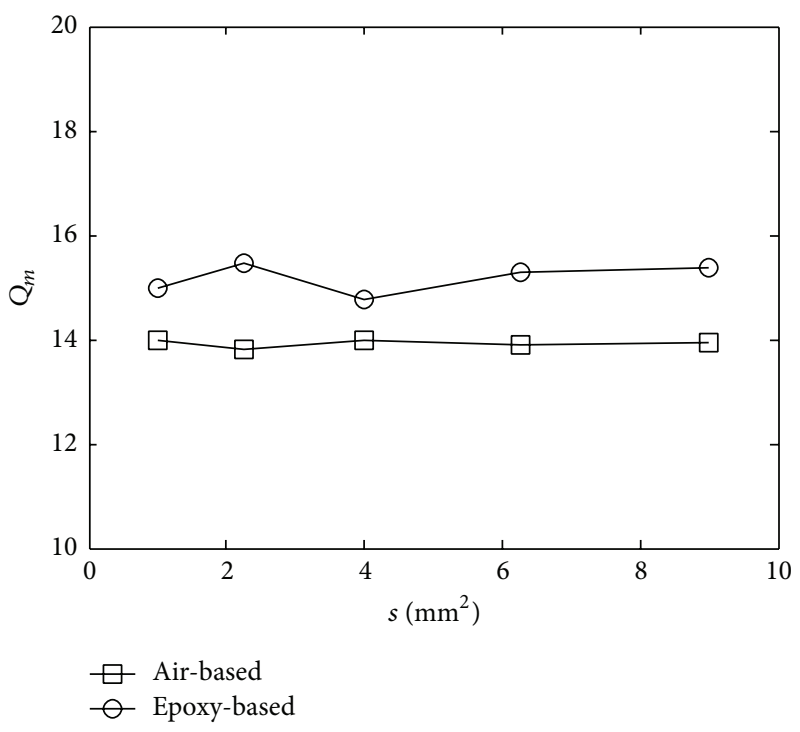

FIGURE 10: Influence of the PZT cross-sectional area on the mechanical quality factor.

In the finite element model, the cross-sectional area $s$ and the volume fraction $\varphi$ of PZT are $1 \mathrm{~mm} \times 1 \mathrm{~mm}$ and $40 \%$. The thickness of piezoelectric column is gradually increased from $5 \mathrm{~mm}$ to $10 \mathrm{~mm}$, with the interval of $1 \mathrm{~mm}$.

As is shown in Figures 11 and 12, the electromechanical conversion efficiency $K_{t}$ and the mechanical quality factor $Q_{m}$ both vary slightly with the increase of the thickness of PZT $h$. However, when the volume fraction of $\operatorname{PZT} \varphi$ is constant, with the increase of the PZT thickness $h$, the center frequency of air-coupled 1-3 piezoelectric composites is almost linearly decreasing, as is shown in Figure 13. Therefore, according to the desired center frequency, the appropriate thickness of the piezoelectric composites should be designed.

According to the results of the above simulation analysis, the volume fraction of PZT is $\varphi=40 \%$ to ensure the optimal electromechanical conversion efficiency and to keep the low acoustic impedance. The side length of PZT column is $a=$ $1 \mathrm{~mm}$ to limit the lateral vibration mode. The thickness of the sensitive element is $h=10 \mathrm{~mm}$ to ensure the center frequency of the air-coupled transducers to be about $200 \mathrm{kHz}$. 


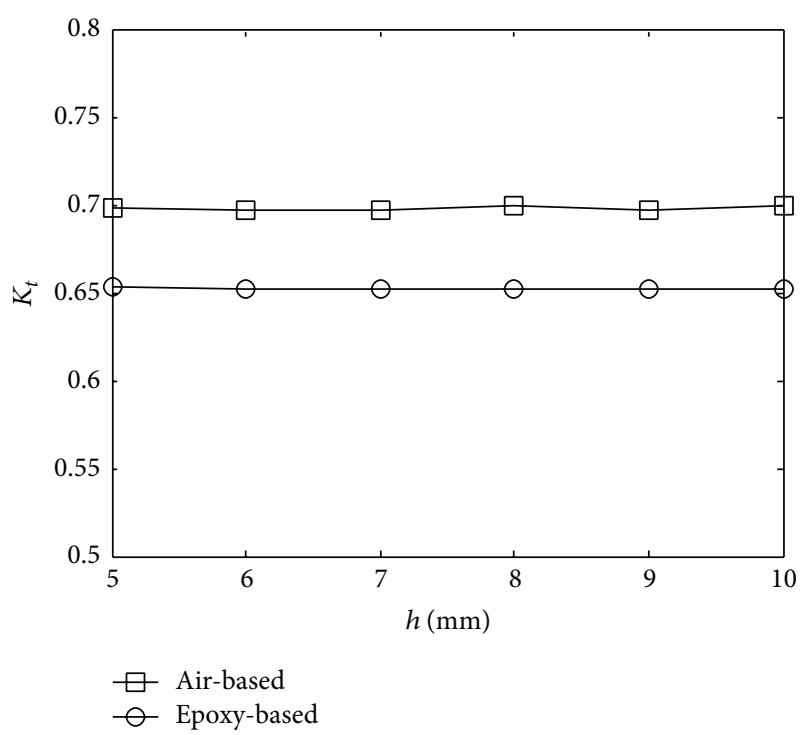

FIGURE 11: Influence of the ceramic thickness on the electromechanical coupling coefficient.

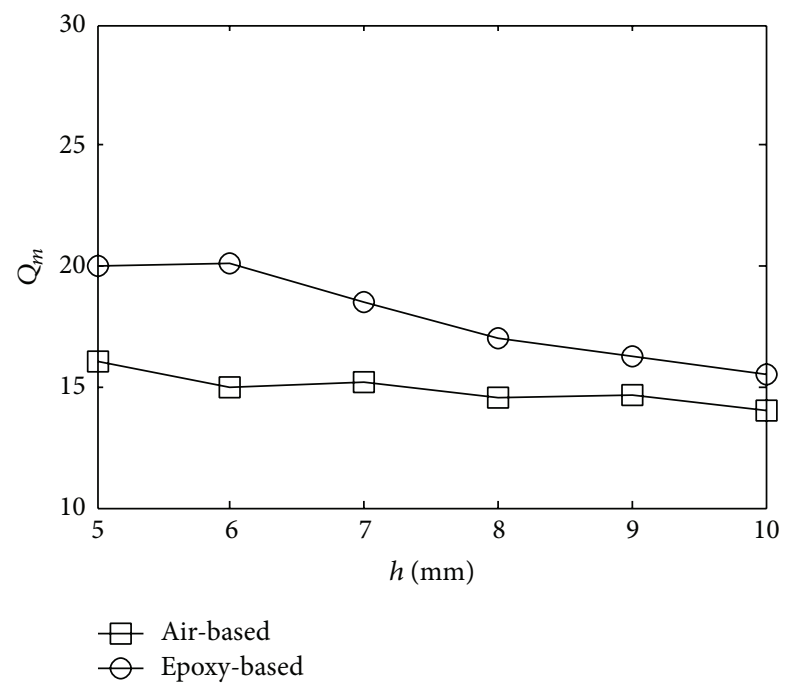

FIGURE 12: Influence of the ceramic thickness on the mechanical quality factor.

\section{Fabrication and Performance Test of Air-Coupled Transducer}

3.1. Air-Coupled Transducer Preparation and Impedance Characteristics Analysis. Since the substrate of the air-based 13 piezoelectric composite is intensive honeycomb structure, the traditional mechanical method is not feasible for the fabrication. In this research, the honeycomb structures made of resin are constructed by the method of $3 \mathrm{D}$ printing technology, with the $30 \%$ volume fraction of air.

The ProJet 3510 SD (3D Systems, USA) 3D printer is used to fabricate the honeycomb structure, with the resin material of VisiJet Crystal. The honeycomb structure is divided into several layers and printed layer by layer. The resolution of the

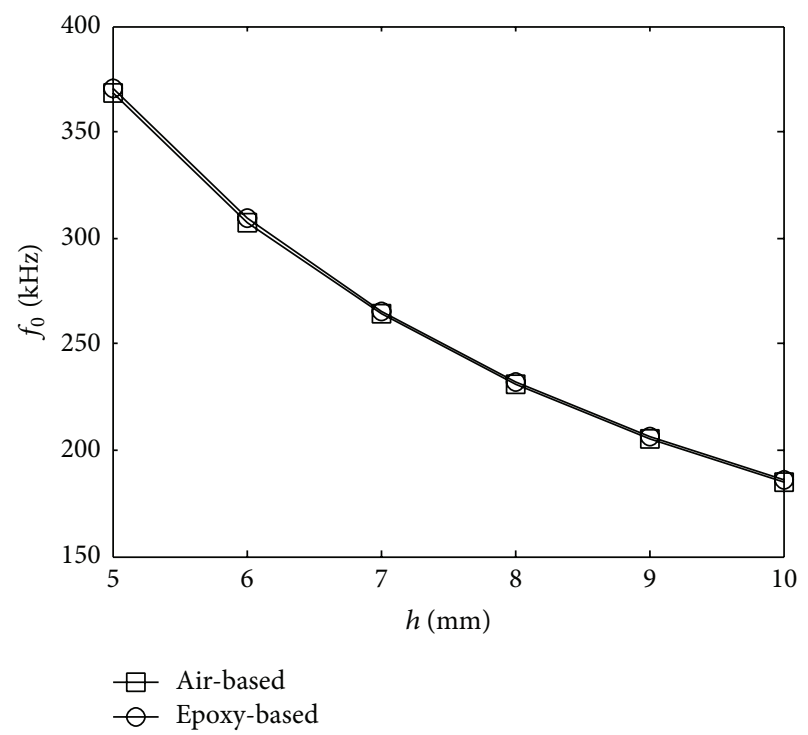

FIGURE 13: Influence of the ceramic thickness on the center frequency.

TABLE 3: Frequency of series resonant and parallel resonant of transducers.

\begin{tabular}{lcc}
\hline Number & $f_{s}$ & $f_{p}$ \\
\hline 1 & $147.2 \mathrm{kHz}$ & $166.1 \mathrm{kHz}$ \\
2 & $155.3 \mathrm{kHz}$ & $181.2 \mathrm{kHz}$ \\
3 & $146.1 \mathrm{kHz}$ & $167.9 \mathrm{kHz}$ \\
\hline
\end{tabular}

$3 \mathrm{D}$ printer is $32 \mu \mathrm{m}$ to make sure the precision of the structure is at $0.025 \mathrm{~mm}-0.05 \mathrm{~mm}$. Then, a precise honeycomb structure will be obtained. The piezoelectric columns are manually inserted into the honeycomb structures, both combined by epoxy adhesive. After curing, the upper and bottom surfaces are polished. Then, the gold is sputtered on the two surfaces as electrodes. Finally, when the air-based 1-3 piezoelectric composites are packaged up with the shield, the air-coupled transducer will be complete, as shown in Figure 14. The impedance characteristics of the air-coupled transducers are measured by an impedance analyzer (Agilent 4294A). The results are shown in Figure 15. The characteristic impedance curves of the transducers differ a little. The frequencies of series resonant $f_{s}$ and parallel resonant $f_{p}$, shown in Table 3 , are slightly different. Meanwhile, because the aspect ratio of the piezoelectric column is relatively small, the lateral vibration mode is far away from the thickness vibration mode. So, the pure thickness vibration mode is approached.

3.2. Air-Coupled Transducer Performance Test. The aircoupled transducers are tested. The transducer arrangement is shown in Figure 16. The distance between the transmitting transducer and the receiving transducer is $80 \mathrm{~mm}$. The direct wave signals transmitted through the air are detected.

The excitation signal is a 5 -cycle $200 \mathrm{kHz}$ sinusoidal tone burst, modulated by a Hanning window. The received signals are shown in Figure 17. As can be seen from the results, the air-coupled transducers can both excite and receive the 


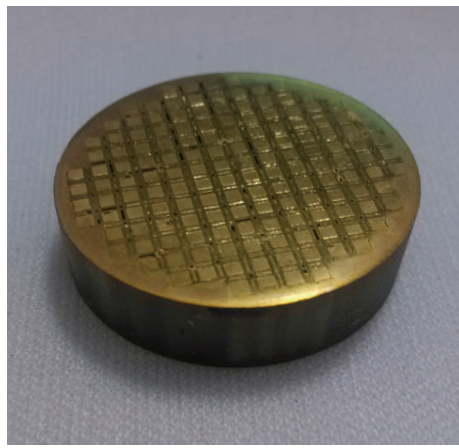

(a)

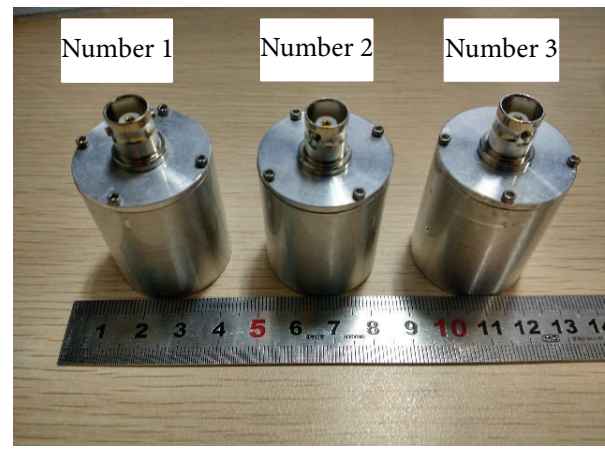

(b)

FIGURE 14: Schematic representation of 1-3 piezoelectric composite and air-coupled transducers: (a) air-based 1-3 piezoelectric composite and (b) air-coupled transducers.

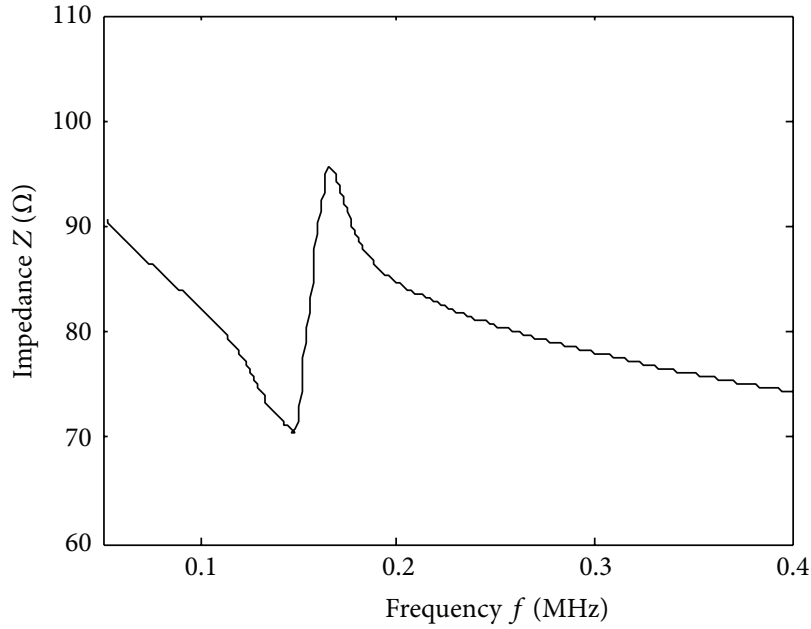

(a)

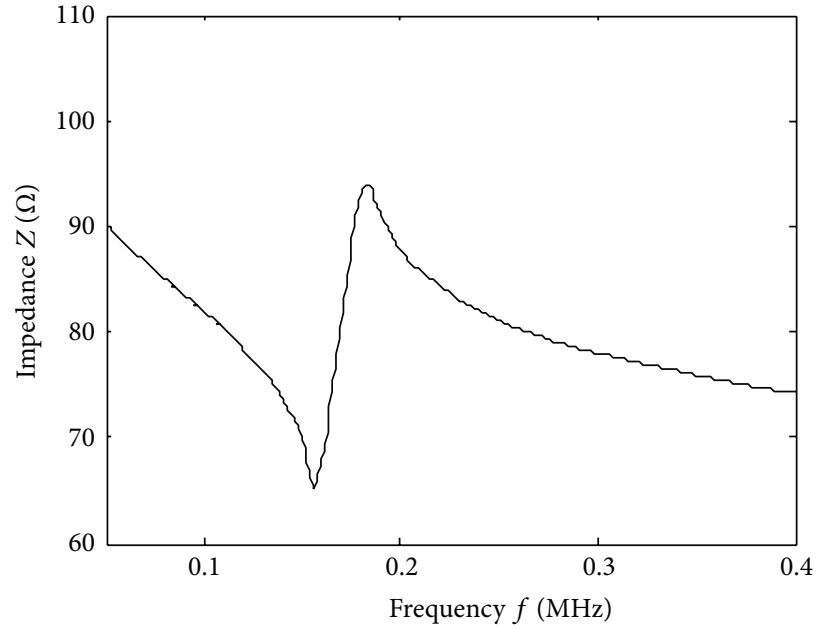

(b)

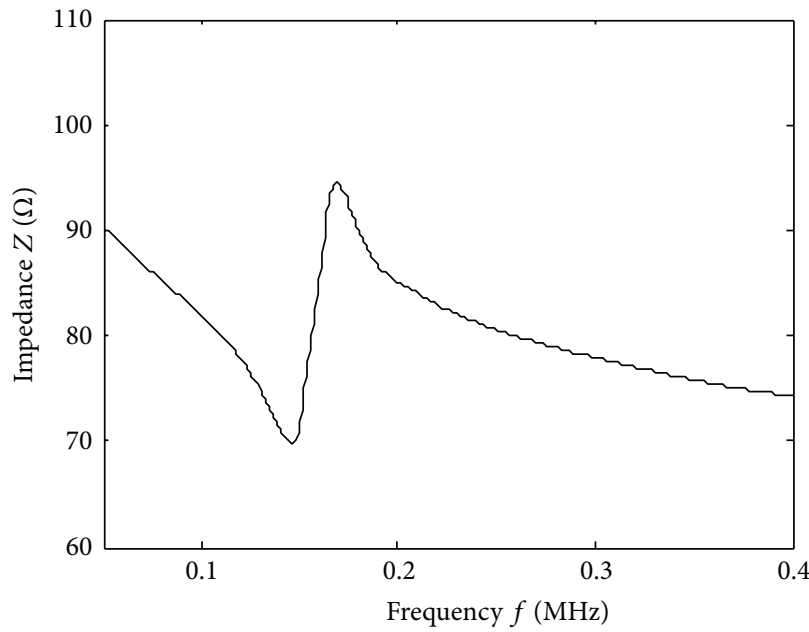

(c)

FIGURE 15: Impedance curves of air-coupled transducers: (a) number 1, (b) number 2, and (c) number 3. 


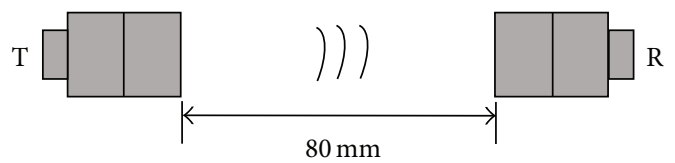

FIGURE 16: Transducer arrangement of testing experiment.
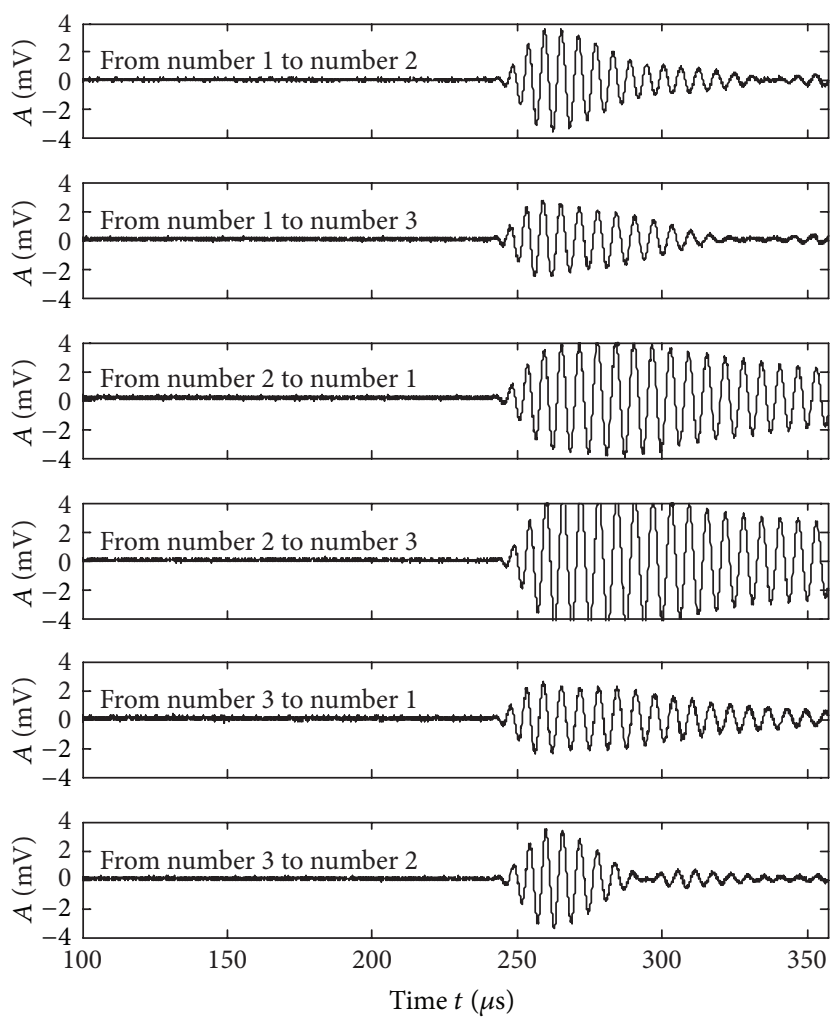

FIGURE 17: Performance test results of air-coupled transducers at $200 \mathrm{kHz}$.

ultrasound in the air, and the signal-to-noise ratio (SNR) of direct wave signals seems to be very well. According to the received waveform signals, in the subsequent experiment of defect detection, number 3 transducer is selected as transmitter to emit an ultrasonic pulse, while number 2 transducer is selected as receiver.

According to the fabrication and performance test of aircoupled transducer, it is feasible to introduce $3 \mathrm{D}$ printing method to fabricate a transducer. However, because all of the air-coupled transducers are handmade, the consistency is not very good. Hence, the excitation and reception performance of air-coupled transducers differ. Meanwhile, as the transducers do not include matching and backing layer, the received waveforms trail a lot.

\section{Experiment of Defect Detection}

Lamb waves are ultrasonic guided waves formed by the superposition of longitudinal and transverse waves propagating in a plate-like structure in which the thickness is comparable

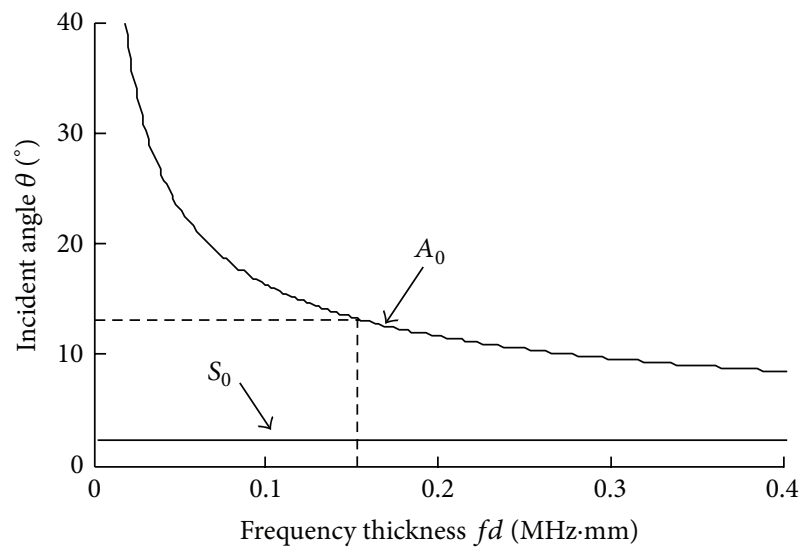

FIGURE 18: Incident angle dispersion curves of Lamb waves along $\langle 110\rangle$ orientation for monocrystalline silicon wafer.

to the wavelength. Lamb waves can travel relatively long distances with little attenuation in plate structures [17], and they are sensitive to both surface and subsurface discontinuities [18].

The Lamb wave, generated by air-coupled transducers, is introduced into the production and quality control process of monocrystalline silicon, and the final purpose is to determine and detect the defects nondestructively [19]. Due to the center frequency of excitation and the thickness of the plates, different symmetric mode $\left(S_{0}\right)$ and antisymmetric mode $\left(A_{0}\right)$ should be induced. In this case, $200 \mathrm{kHz}$ is chosen as the excitation frequency. The signal received by air-coupled transducer is the leaky wave from the silicon surface. $S_{0}$ mode possesses mainly in-plane displacement, whereas outof-plane displacement is dominant in $A_{0}$ mode [20]. Thus, $A_{0}$ mode can be easier to be collected with air-coupled ultrasonic transducers. Meanwhile, the wavelength of $A_{0}$ mode is shorter than that of $S_{0}$ mode at the same frequency.

When ultrasonic waves travel through air and hit the air/plate interface at an angle, both reflected and refracted waves are produced. After multiple reflections and mode conversion, one or more Lamb wave modes are excited. In order to excite Lamb wave at a specific frequency, the incident angle should satisfy Snell's law, formulated by [21]

$$
\sin \theta=\frac{c_{\mathrm{air}}}{c_{p}},
$$

where $\theta$ is the incident angle, $c_{\text {air }}$ is the velocity of the wave propagating in air, and $c_{p}$ is the phase velocity of the Lamb wave. As the velocity of air and the phase velocity of Lamb waves are known, incident angle disperse curves of Lamb waves along $\langle 110\rangle$ direction of monocrystalline silicon can be obtained by solving (5). The results are shown in Figure 18. These curves help in optimizing the orientation of the transmitting and receiving air-coupled ultrasonic transducers. According to the results, the theoretical coincidence incident angle for $A_{0}$ mode at $200 \mathrm{kHz}$ should be $13^{\circ}$.

4.1. Air-Coupled Ultrasonic Experiment System. The experimental set-up consists of a high power signal generator, 


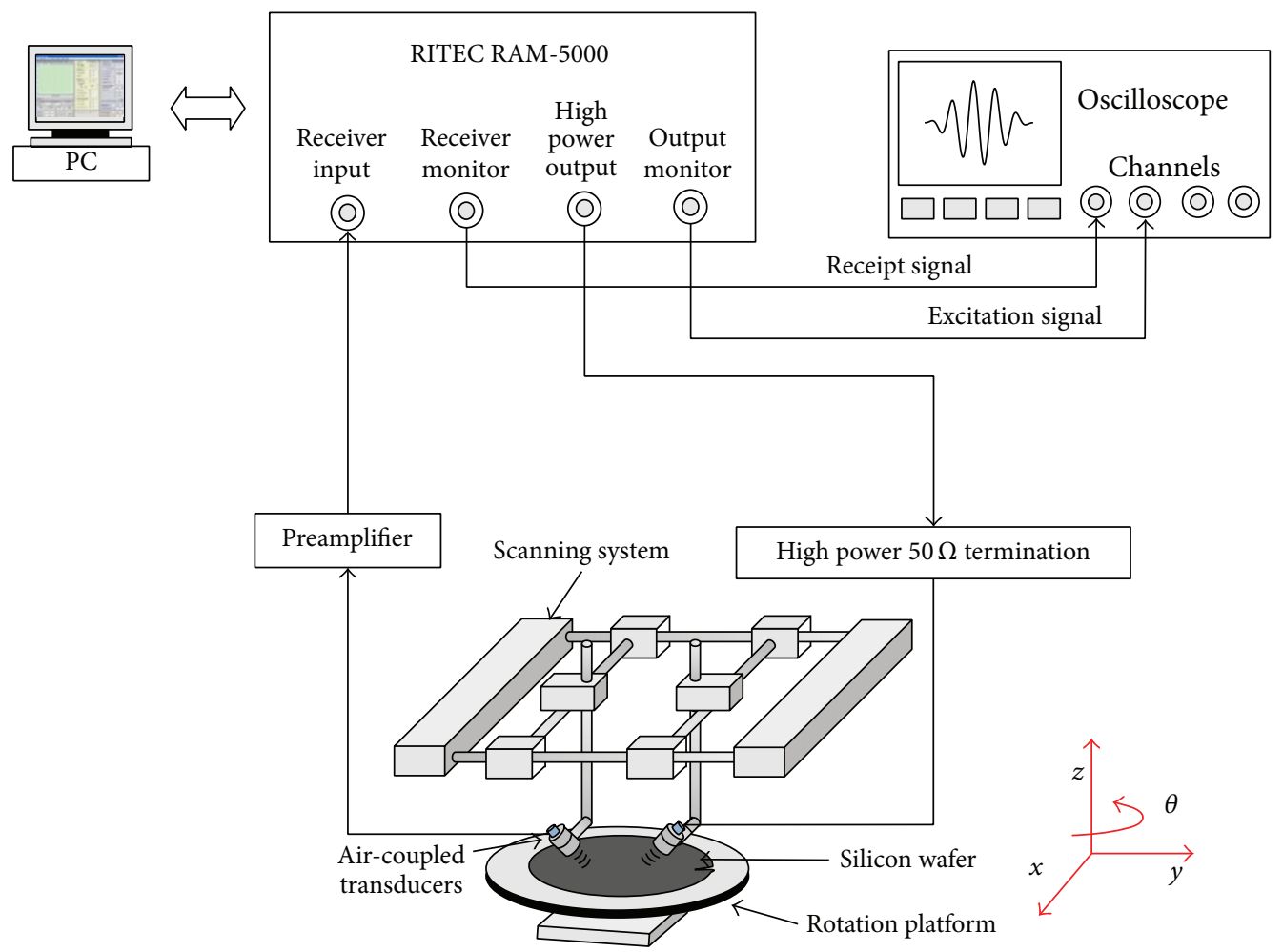

FIGURE 19: The diagram of air-coupled ultrasonic detection system.

a high $\mathrm{dB}$ preamplifier, high power $50 \Omega$ termination, a personal computer, an oscilloscope, and a scanning system. The schematic diagram of experimental set-up is shown in Figure 19. The SNAP RAM-5000 (RITEC, USA) ultrasonic measurement system is used to generate high power tone burst signals for excitation of the transmitting transducer (number 3 ) and to receive signals from the receiving transducer (number 2) with its preamplifier. The signal is then acquired by an oscilloscope (DPO4054, Tektronix, USA) with a sampling frequency of $50 \mathrm{MHz}$. A pair of transducer fixtures are used to hold and orient the air-coupled ultrasonic transducers at a special angle for exciting and receiving Lamb waves.

4.2. Specimens. Monocrystalline silicon, shown in Figure 20, is supplied in the form of plate with a crystal orientation of (001), whose diameter is $200 \mathrm{~mm}$ and thickness is $725 \mu \mathrm{m}$, and the size of the crack defect is $15 \mathrm{~mm} \times 0.5 \mathrm{~mm} \times 0.5 \mathrm{~mm}$ with the direction of $\langle 110\rangle$.

4.3. Experiments and Results. The transmitting transducer and the receiving transducer are arranged in the same side above the silicon wafer surface, with the fixed distance of $80 \mathrm{~mm}$, scanning along the direction of the crack detection. The incident angle of transmitter $\theta_{\mathrm{T}}$ kept equal to the receiver $\theta_{\mathrm{R}}$ is $13^{\circ}$. The scanning distance is totally $50 \mathrm{~mm}$ in step of $2 \mathrm{~mm}$. The excitation signal is also a 5 -cycle $200 \mathrm{kHz}$ sinusoidal tone burst modulated by a Hanning window. The signals received at both the defect-free position and defective position are shown in Figure 21.

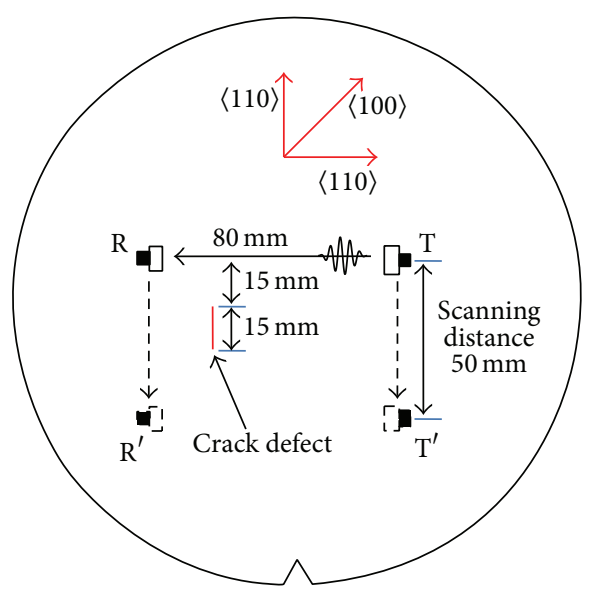

FIGURE 20: Sample of monocrystalline silicon and transducer set-up.

In usual process of defect detection, the amplitude of direct wave that transmits through the defect is used to describe the presence and the size of the defects. In this experiment, the influence of the presence of cracks on the amplitude of signals is not that obvious. So, it is difficult to distinguish the location of the defect accurately based on amplitude characteristics.

However, when Lamb waves propagate through the crack, not only will the amplitude change, but also the phase will shift or distort. The correlation coefficient of the received signal and the reference signal is calculated to extract the 


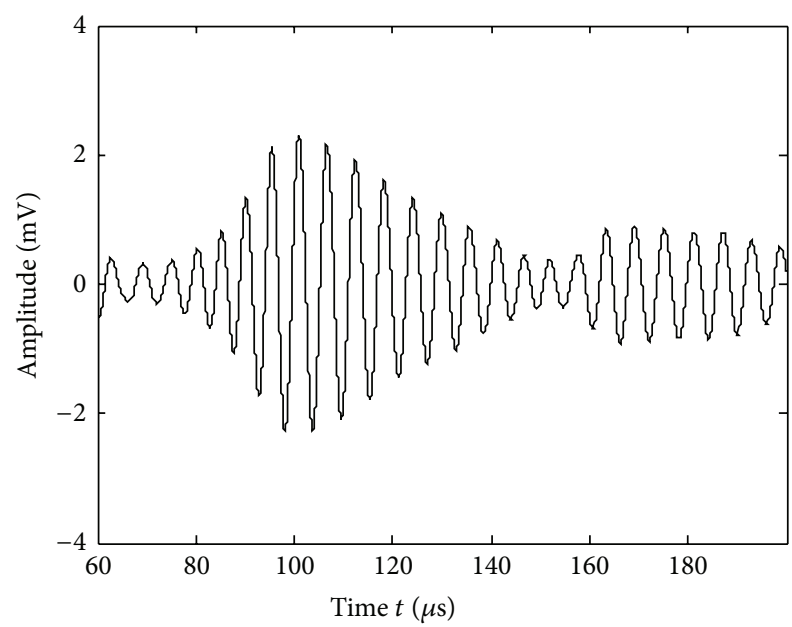

(a)

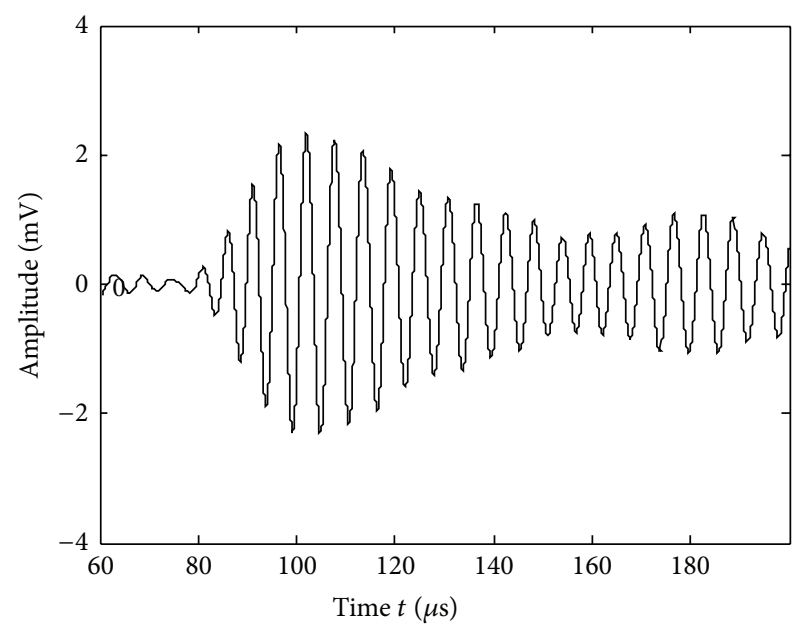

(b)

FIGURE 21: Received signals for (a) defect-free position and (b) defective position.

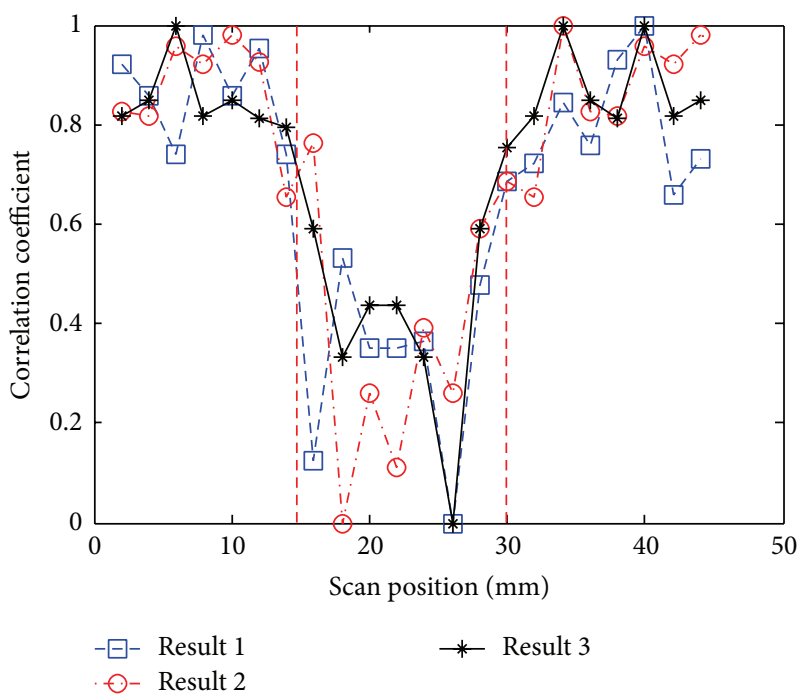

FIGURE 22: Correlation coefficient between reference signals and reception signals.

influence of the crack on the signals [22]. The rectangular window is used to intercept the received signals of Lamb wave, and the signal of defect-free position is used as reference signal. The correlation coefficients of all the received signals and reference signal are calculated and established the corresponding relationship with the scan position. The results can be seen in Figure 22. The experiment has been implemented for 3 times. All of the results show that the correlation coefficients of the received signals at defective position are lower, which means the waveforms have been distorted when Lamb wave travels across the defect. The correlation coefficient of 0.6 is chosen as the threshold. The defect position determined by this method is conformed with the actual defect position. It proved that the method is feasible in monocrystalline silicon defect detection.

\section{Conclusion}

In this research, a new structure of air-based 1-3 piezoelectric composites is introduced. The influence of the structural parameters on the performance of air-based 1-3 piezoelectric composites has been investigated through finite element analysis. According to the results of simulation, the air-based 1-3 piezoelectric composites and air-coupled transducers are fabricated with the PZT volume fraction $\varphi=40 \%$; meanwhile, the side length of PZT column $a=1 \mathrm{~mm}$ and the thickness of the sensitive element $h=10 \mathrm{~mm}$. All of the air-coupled transducers can excite and receive the ultrasound in air effectively, and the signal-to-noise ratio (SNR) of direct wave seems to be very well.

Scanning method is used to detect the crack defect in the monocrystalline silicon wafer by Lamb waves. The direct wave of $A_{0}$ mode is used to identify the defect. Results reveal that the location and size of the defect can be detected by calculating the correlation coefficient of the received signals and reference signals. It proved that this method is feasible in monocrystalline silicon defect detection.

To sum up, the 3D printed air-based 1-3 piezoelectric composites structures are appropriate to fabricate the aircoupled transducers. They can both reduce the acoustic impedance and enhance the electromechanical conversion efficiency. In future studies, matching/backing layer should be taken into account to improve the performance of aircoupled transducers.

\section{Competing Interests}

The authors declare that there are no competing interests regarding the publication of this paper.

\section{Acknowledgments}

The work in this paper is financially supported by the National Natural Science Foundation of China (Grant 
nos. 11372016 and 51235001) and the Outstanding Young Researcher Program from Organization Department of the CPC Beijing Municipal Committee (Grant no. 2014000020124G038).

\section{References}

[1] A. Belyaev, O. Polupan, W. Dallas, S. Ostapenko, D. Hess, and J. Wohlgemuth, "Crack detection and analyses using resonance ultrasonic vibrations in full-size crystalline silicon wafers," Applied Physics Letters, vol. 88, no. 11, Article ID 111907, 2006.

[2] G. Yun, K.-M. Kim, Y. Roh, Y. Min, J.-K. Lee, and Y. H. Kim, "Comparison of slowness curves of Lamb wave with elastic moduli and crystal structure in silicon wafers," in Proceedings of the IEEE International Ultrasonics Symposium (IUS '13), pp. 1598-1601, IEEE, Prague, Czech Republic, July 2013.

[3] S.-H. Kee and J. Zhu, "Using air-coupled sensors to determine the depth of a surface-breaking crack in concrete," Journal of the Acoustical Society of America, vol. 127, no. 3, pp. 1279-1287, 2010.

[4] O. Balogun, G. D. Cole, R. Huber, D. Chinn, T. W. Murray, and J. B. Spicer, "High-spatial-resolution sub-surface imaging using a laser-based acoustic microscopy technique," IEEE Transactions on Ultrasonics, Ferroelectrics, and Frequency Control, vol. 58, no. 1, pp. 226-233, 2011.

[5] Z. Zhou and D. Wei, "Progress of air-coupled ultrasonic nondestructive testing technology," Chinese Journal of Mechanical Engineering, vol. 44, no. 6, pp. 10-14, 2008.

[6] H. B. Kichou, J. A. Chavez, A. Turo, J. Salazar, and M. J. Garcia-Hernandez, "Lamb waves beam deviation due to small inclination of the test structure in air-coupled ultrasonic NDT," Ultrasonics, vol. 44, pp. e1077-e1082, 2006.

[7] I. Y. Solodov, R. Stoessel, and G. Busse, "Material characterization and NDE using focused slanted transmission mode of aircoupled ultrasound," Research in Nondestructive Evaluation, vol. 15, no. 2, pp. 65-85, 2004.

[8] F. Yan, E. Hauck, T. M. Pera et al., "Ultrasonic guided wave imaging of a composite plate with air-coupled transducers," in Review of Progress in Quantitative Nondestructive Evaluation, pp. 1007-1012, AIP Publishing, 2007.

[9] S. K. Chakrapani, M. J. Padiyar, and K. Balasubramaniam, "Crack detection in full size $\mathrm{Cz}$-silicon wafers using lamb wave air coupled ultrasonic testing (LAC-UT)," Journal of Nondestructive Evaluation, vol. 31, no. 1, pp. 46-55, 2012.

[10] Z. Liu, H. Yu, C. He, and B. Wu, "Delamination damage detection of laminated composite beams using air-coupled ultrasonic transducers," Science China: Physics, Mechanics and Astronomy, vol. 56, no. 7, pp. 1269-1279, 2013.

[11] R. E. Newnham, D. P. Skinner, and L. E. Cross, "Connectivity and piezoelectric-pyroelectric composites," Materials Research Bulletin, vol. 13, no. 5, pp. 525-536, 1978.

[12] G. Hayward and J. Bennett, "Assessing the influence of pillar aspect ratio on the behavior of 1-3 connectivity composite transducers," IEEE Transactions on Ultrasonics, Ferroelectrics, and Frequency Control, vol. 43, no. 1, pp. 98-108, 1996.

[13] A.-C. Hladky-Hennion and J.-N. Decarpigny, "Finite element modeling of active periodic structures: application to 1-3 piezocomposites," Journal of the Acoustical Society of America, vol. 94, no. 2 I, pp. 631-635, 1993.

[14] M. Bhardwaj, "Piezoelectric transducer with gas matrix," WO2004017369 A2, 2007, 2003.
[15] W. A. Smith and B. A. Auld, "Modeling 1-3 composite piezoelectrics: thickness-mode oscillations," IEEE Transactions on Ultrasonics, Ferroelectrics, and Frequency Control, vol. 38, no. 1, pp. 40-47, 1991.

[16] T. R. Gururaja, W. A. Schulze, L. E. Cross et al., "Resonant modes of vibration in piezoelectric PZT-polymer composites with two dimensional periodicity," Ferroelectrics, vol. 54, no. 1, pp. 183-186, 1984.

[17] J. L. Rose, "A baseline and vision of ultrasonic guided wave inspection potential," Journal of Pressure Vessel Technology, vol. 124, no. 3, pp. 273-282, 2002.

[18] M.-K. Song and K.-Y. Jhang, "Crack detection in singlecrystalline silicon wafer using laser generated Lamb Wave," Advances in Materials Science and Engineering, vol. 2013, Article ID 950791, 6 pages, 2013.

[19] M.-K. Song and K.-Y. Jhang, "Crack detection in singlecrystalline silicon wafer using laser generated Lamb wave," Advances in Materials Science and Engineering, vol. 2013, Article ID 950791, 6 pages, 2013.

[20] Z. Su, L. Ye, and Y. Lu, "Guided Lamb waves for identification of damage in composite structures: a review," Journal of Sound and Vibration, vol. 295, no. 3-5, pp. 753-780, 2006.

[21] M. Castaings, P. Cawley, R. Farlow, and G. Hayward, "Single sided inspection of composite materials using air coupled ultrasound," Journal of Nondestructive Evaluation, vol. 17, no. 1, pp. 37-45, 1998.

[22] R. Cepel, K. C. Ho, B. A. Rinker, D. D. Palmer Jr., T. P. Lerch, and S. P. Neal, "Spatial correlation coefficient images for ultrasonic detection," IEEE Transactions on Ultrasonics, Ferroelectrics, and Frequency Control, vol. 54, no. 9, pp. 1841-1849, 2007. 


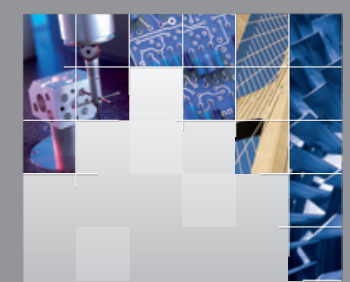

\section{Enfincering}
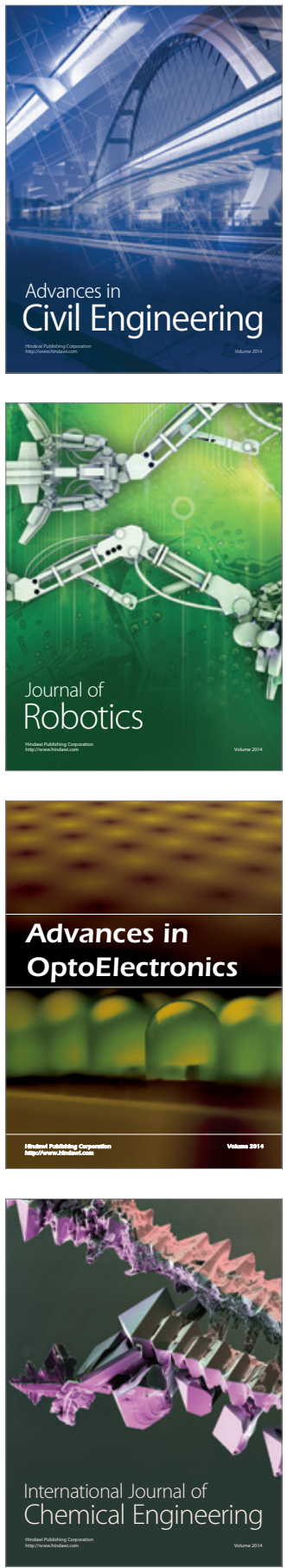

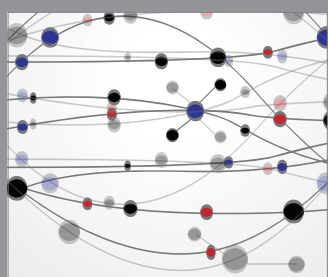

The Scientific World Journal

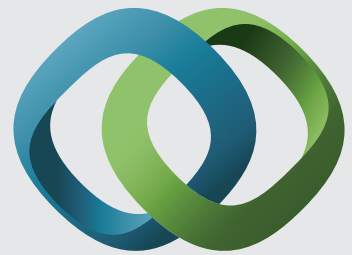

\section{Hindawi}

Submit your manuscripts at

http://www.hindawi.com
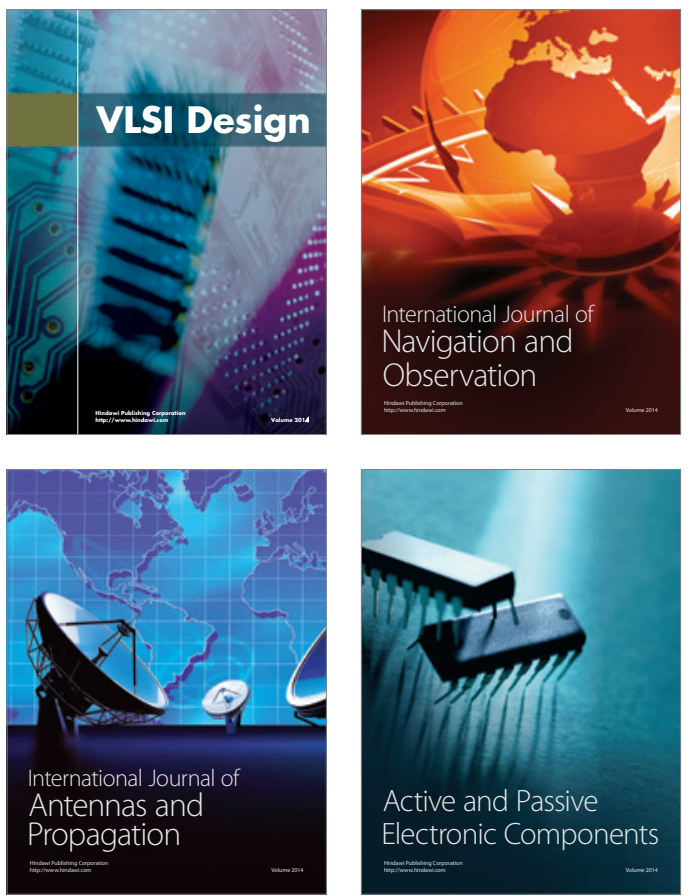
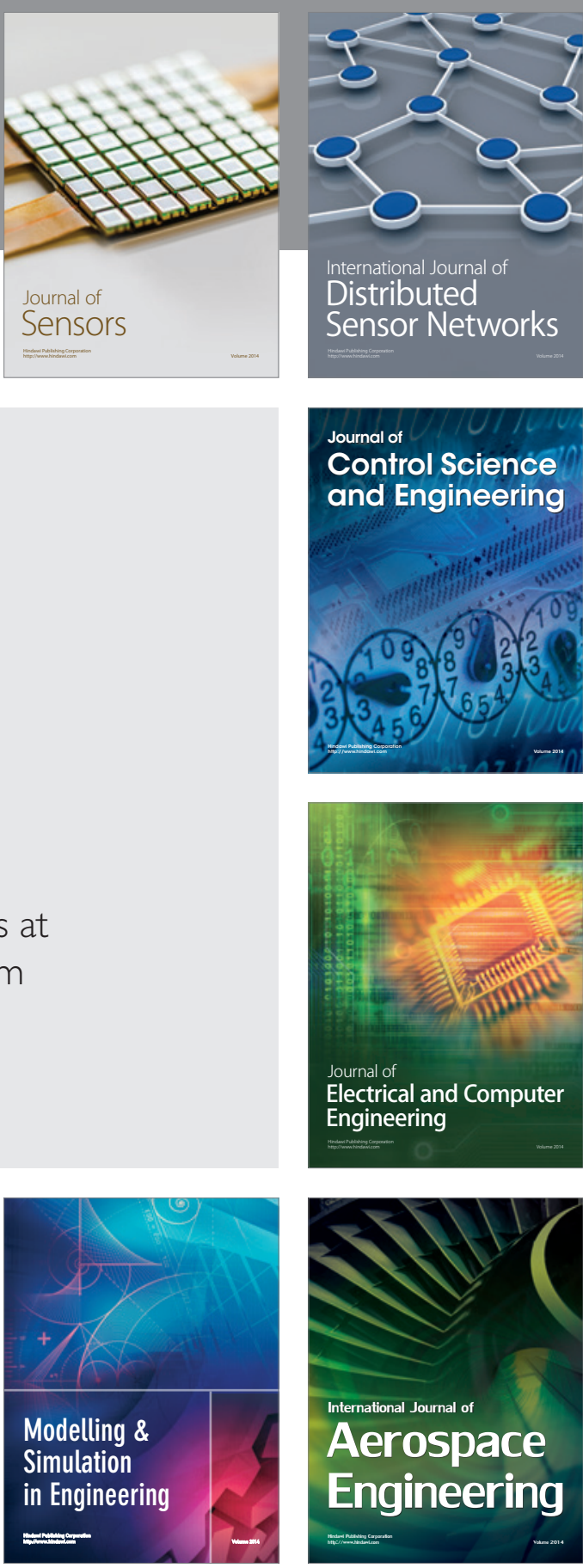

International Journal of

Distributed

Sensor Networks

Journal of

Control Science

and Engineering
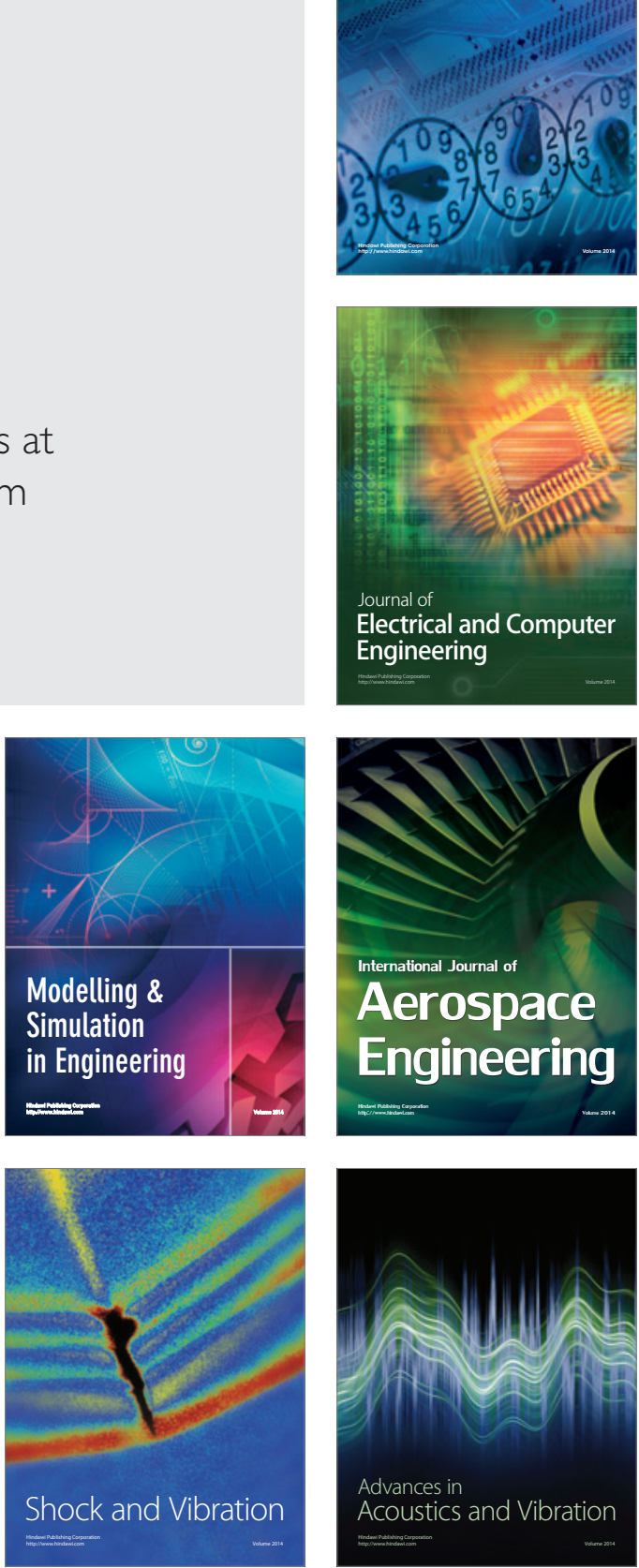